\title{
Parry-Romberg syndrome: Which side of your face looks better?
}

\author{
Hui Lian Hoํ․ Ahmad Halim², and Wan Azman Wan Sulaiman² \\ ${ }^{1}$ Universiti Malaysia Sabah \\ ${ }^{2}$ Universiti Sains Malaysia - Kampus Kesihatan
}

February 22, 2021

\begin{abstract}
Parry-Romberg syndrome (PRS) is a rare facial deformity characterised by slowly progressive hemifacial atrophy. We present a new case of hemifacial atrophy in an 18-year-old lady. Rudimentary understanding of the pathogenesis poses a challenge in deciding optimal timing and surgical intervention. Current suggested management are reviewed and discussed.
\end{abstract}

\section{Hosted file}

Wiley - Parry Romberg syndrome.pdf available at https://authorea.com/users/397365/articles/ 510260-parry-romberg-syndrome-which-side-of-your-face-looks-better 

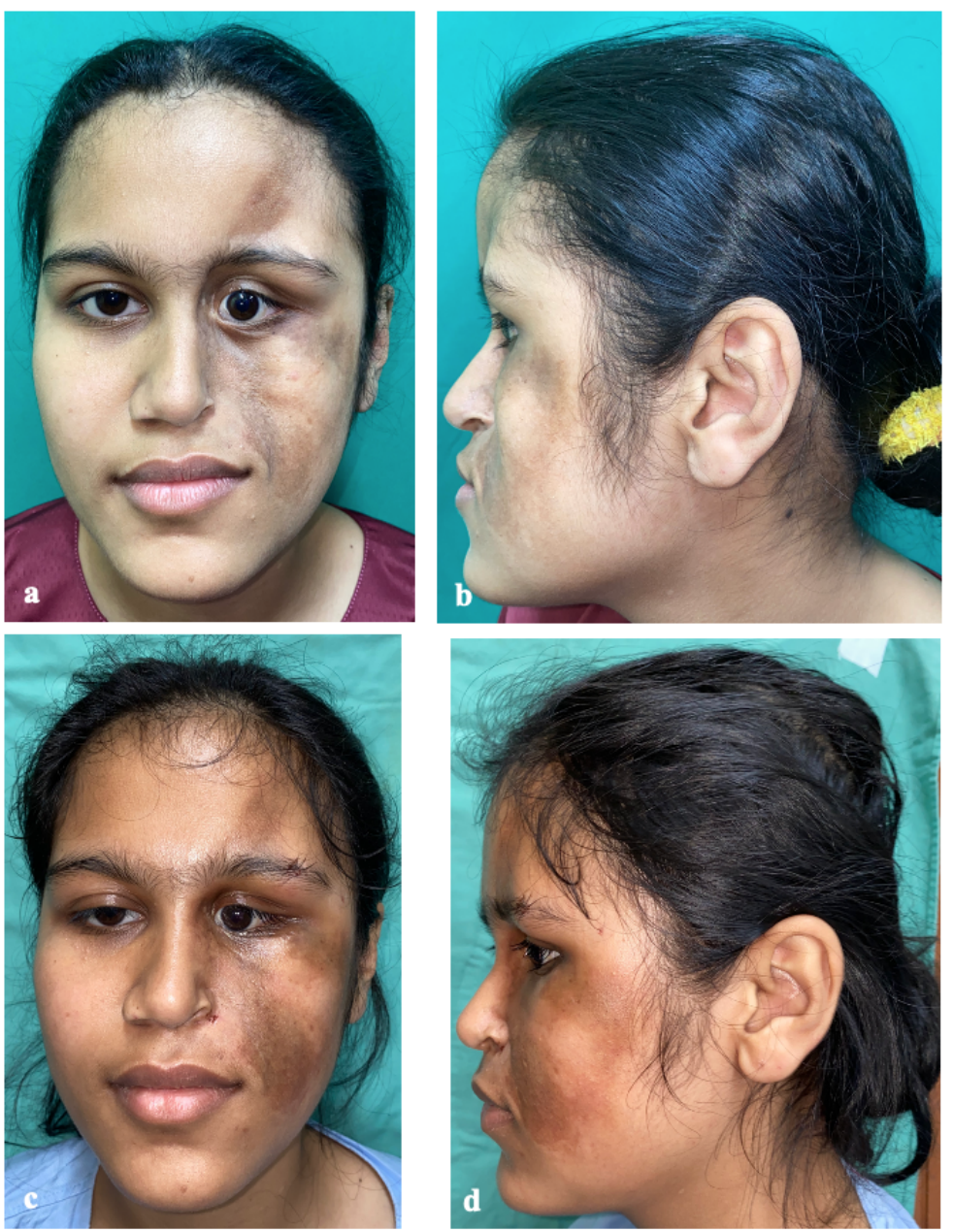

Figure 1: $a$, b: Left-sided unilateral facial atrophy with ipsilateral enophthalmos and deviation of the oral commissure and nose toward the affected side. Coup de sabre sign is observed in this patient. Overlying skin appeared indurated and hyperpigmented. c,d: Improvement of the facial contour seen, especially over the forehead, cheek and nasolabial region after $50 \mathrm{~mL}$ autologous lipotransfer. Indurated area of skin appeared more supple. 


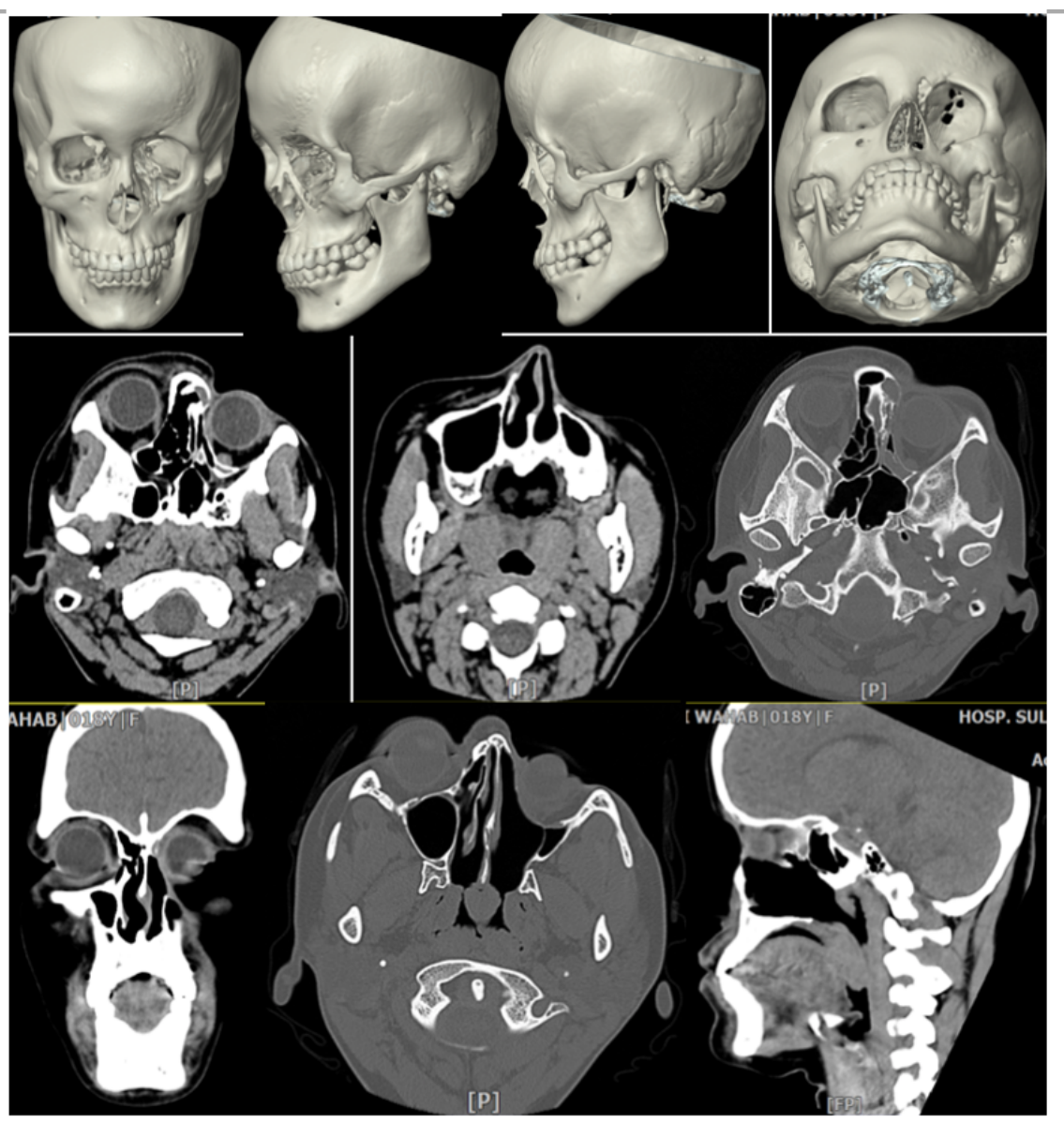

Figure 2: Thinning of the frontal and zygomatic processes of maxilla, the frontal bone; absence of left medial orbital floor and the atrophied overlying soft tissues seen. 